\title{
EXPLOSIONS IN THE OPERATING THEATRE
}

\author{
By J. Alfred LeE, M.R.C.S., L.R.C.P., M.M.S.A., D.A., F.F.A., R.C.S. \\ Consultant Anaesthetist to the Southend-on-Sea Hospitals; King George Hospital, Ilford, etc.
}

Explosions in operating theatres do not occur frequently, but unless there is constant care and watchfulness, such catastrophies can descend with tragic suddenness, and may result in loss of life or limb.

Those who work in operating theatres tend to forget the dangers lurking round the corner. The writer's purpose is to bring these hazards once again to their notice, and to point out afresh some of the methods which should be adopted to prevent their occurrence.

Quite recently the U.S. National Fire Protection Association Committee on Hospital Operating Rooms (r949) has published its recommendations which emphasize many easily applicable precautions which are too often overlooked. This report is full of common sense, and deals especially with the prevention of electrostatic sparks.

Most of the volatile anaesthetics in common use are explosive and inflammable when their vapour is diluted with oxygen or nitrous oxide, and the mixtures thus formed will readily ignite. They are more explosive than when such vapours are mixed with air. Diethyl and divinyl ethers come into this category as does the gas cyclopropane. Trichlorethylene and chloroform when used in concentrations suitable for anaesthesia are not inflammable, nor is the unsupplemented mixture of nitrous oxide and oxygen. The vapour of ethyl chloride will burn in air with the formation of choking fumes of hydrochloric acid, but will not cause a dangerous explosion.

As it is almost impossible to exclude, all the time, the accumulation of explosive mixtures of gas and vapour from operating theatres, safety must be looked for in eliminating all sources of ignition, especially electrostatic sparks. High atmospheric humidity in the theatre is not reliable in preventing such sparks.

Under average conditions, explosive anaesthetic mixtures become diluted with the air of the theatre to a non-inflammable percentage before reaching a distance of two feet from a point of leak of anaesthetic vapours involving the quantities of these vapours used in ordinary surgical procedures. When ether is used however, an additional risk is present if the container breaks or spills and liquid falls to the floor to give off vapour.

Because of the high rate of gas diffusion and dispersion, factors of ventilation, draughts, etc., have little effect on the concentration of explosive gases in the limited area round the head of the patient and the anaesthetic machine.

\section{The Source of Ignition}

This may be a spark from an electric current; it may be a hot surface or body in the theatre; ignition may arise spontaneously; whilst lastly, and of greatest importance, it may be due to electrostatic sparks.

\section{Ignition from Electric Current}

Permanent electrical equipment such aso switches, X-ray viewing boxes, bells, telephones etc., should be fixed not less than five feet from the floor of anaesthetic rooms and operating theatres. When installed at a lower level, switches should be of explosion-proof design. An easily procurable type of explosion-proof switch consists of a sealed glass tube having two side arms filled with mercury, one carrying the afferent, the other the efferent electric wire. The act of switching on the current tilts the tube and allows a bead of mercury contained in it to bridge the gap between the two electrodes, so effecting electrical continuity and a. free flow of current. Any sparking which occurs is isolated within the sealed glass tube.

All portable electrical apparatus should be explosion-proof and should be fitted with threewire-flex, the third wire joining the outer casing of the machine to an earth in the wall plug. The plug point should incorporate an interlocking mechanism which makes it impossible to put in or to pull out the plug while the current is switched on.

The cautery and diathermy should only be used with explosive mixtures if the minimal distance between the spark from the electrode or the machine, and a possible point of leak from the anaesthetic closed circuit is more than two feet. A little thought makes it clear that explosive mixtures cannot exist at any great distance from a 
point of leak as the proportions of anaesthetic vapour in air or oxygen that are effective for anaesthesia are very much the same as the proportions present in the inflammable range of such mixtures. It is interesting to consider the position that would arise if anaesthetic mixtures in the explosive (i.e. anaesthetic) range were to reach even as far as the head of the anaesthetist. There might well be some justification for the surgeon's old jibe that an anaesthetist is an individual who is mostly asleep over the head of a patient who is mostly awake !

Inflammable anaesthetics should not ordinarily be given while the $\mathrm{X}$-ray machine is in operation. If they must be used in patients about to undergo radiography, such mixtures should be discontinued some minutes before the current is switched on, and a non-inflammable mixture substituted. Thus, when it is necessary to give a general anaesthetic to a child for bronchography, for example, ether can be used in the early stages to deepen anaesthesia, and nitrous oxide, oxygen and trilene used afterwards for maintenance.

It should be unnecessary to emphasize that diathermy is unsafe if used in the pleural cavity while the patient is receiving an inflammable anaesthetic. The presence of a broncho-pleural fistula makes even greater care obligatory. It is important to remember that the prolonged use of diathermy may cause a strong positive charge of electricity to accumulate on a patient who is not properly earthed, and this may in turn result in a static spark if a surface of different potential approaches him closely.

The ether bottle should be removed from the anaesthetic machine before the diathermy or cautery are employed, and the key for the cyclopropane cylinder should be laid aside in case the gas should be accidentally turned on.

It is dangerous to overrun small bulbs on endoscopes, and the voltage supplied to them should not exceed the proper figure, 2.5 or 3.5 , for which they are designed. The use of batteries instead of mains transformers will cut down the risk of such accidental overrunning. Foot switches must be explosion proof, as ether vapour, if in excess, may pool near to the ground.

Antiseptic lotions used for painting the skin must be used sparingly if diathermy is to be employed on the skin vessels. Neglect of this elementary precaution has resulted in the spirit catching fire.

Electrical apparatus and wiring should be examined at frequent intervals by a competent person, such as the hospital electrician to see that it is in good repair. To wait for a fault to develop is to court disaster.

\section{Ignition from Heat}

Ether vapour and oxygen have been known to ignite at a temperature of 200 degs. C., so that hot wires and surfaces are a potential source of danger even if they are below the temperature when a dull red glow becomes visible. Certain percentages of ether vapour in air can be ignited by heat to burn with a cool flame which is almost invisible in bright daylight, and which may travel along the line of vapour to its source. Electrostatic sparks will not produce enough heat to initiate this reaction.

\section{Spontaneous Ignition}

Cylinders containing oxygen or nitrous oxide stored at high pressure may explode if they are traumatized or allowed to become very hot as by strong sunlight. If the gases while still under compression are brought into contact with oil or grease, a fire may break out spontaneously and may in turn ignite the anaesthetic vapour. It is for this reason that lubricants are forbidden on the threads of reducing valves.

\section{Ignition from Electrostatic Spark Discharge}

This is the most dangerous type and also the most frequent at the present time. The physics of static spark production has been expertly dealt with by Bulgin et al. (1949) in a recent article.

Static electricity is produced when two dissimilar surfaces are brought into intimate contact and then separated. If a good conductor and a good insulator are charged and then drawn apart, there may be a spark large enough to ignite explosive mixtures. When, on the other hand both surfaces are good conductors, there is no sparking. If any part of the surface of the conducting body is earthed its charge will be dissipated, whereas the whole of the surface of the insulator must be earthed before its charge is lost. A highly charged non-conductor may spark just before it is brought into contact with a conductor.

In the operating theatre, dry blankets and rubber sheeting are the chief articles made of nonconducting material which may become electrostatically charged; the former carries a negative, the latter a positive charge. Rubber, which is ordinarily a non-conductor, acts as a generator of charges and also as an insulator, preventing earthing of, for instance, a patient or piece of apparatus.

The chief solution to this problem lies in arranging for static charges to be carried away to earth. In this way, high potentials will not be built up and sparking will not result.

It is recommend that conducting rubber should be used in operating theatres instead of the 
ordinary non-conducting kind. Rubber becomes a reasonable conductor if it incorporates a quantity of finely divided particles of carbon. This new type of rubber is, apart from its black colour, for practical purposes identical with ordinary rubber. Electrostatic charges occur with the same frequency with it as they do with ordinary rubber, but if the surface is properly earthed, these charges are carried away.

In the operating theatre mattresses, sheeting, footwear, tips for the legs of stools and chairs, trolley tyres, anaesthetic face masks and corrugated tubing should be manufactured from conducting rubber.

The resistance to earth of objects supported on conducting rubber should be $10^{6}-10^{8}$ ohms. Higher or lower values may be dangerous.

The conducting floor should be the common connection through which all objects in the theatre should be intercoupled. The floor makes a more efficient and more convenient intercoupler than the apparatus hanging from the ceiling described by Horton (1939). If the floor is a good conductor it is unnecessary to connect it to a building earth. It has been estimated that the electrical resistance must be greater than 25,000 ohms, but less than 500,000 ohms when measured between two electrodes placed 3 feet apart at any point on the floor. Unfortunately, under these standards, ordinary granolithic floors with inset brass strips are not acceptable, and should give place to floors covered with granolithic base to which has been added suitable amounts of acetylene black or magnesium oxychloride. Certain composition floors are good conductors, while floor coverings of conducting rubber, conducting linoleum and conducting asphalt tile are safe in this respect.

If the electrical resistance of the average theatre floor in use today is tested, it will be found that in many cases a potential danger exists from the point of view of electrostatic explosions.

When floor conductivity has been attained, it becomes necessary for all personnel and equipment to be brought into electrical continuity with the floor.

The patient and the table will be in electrical continuity if a pad of conducting rubber is interposed between them. The wheels of the operating table should either be of metal or should have conducting rubber tyres.

The anaesthetist often finds himself sitting on a stool which has ordinary rubber leg tips and a cushion of the same material to sooth his ischial tuberosities. On his feet he wears rubber-soled shoes, galoshes or Wellingtons, and if he appreciates comfort, he may be found with his feet $\stackrel{\Phi}{\Phi}$ resting on a small platform provided with rubber $c$ tips to its legs to prevent slipping and to ensure silence when it is moved. He is, indeed, in a dangerous situation.

The remedy lies in earthing the stool by conducting rubber leg tips, by converting the rubber $\frac{\bar{N}}{7}$ of the cushion to conducting rubber, or by making $\stackrel{\mathbb{Q}}{\Omega}$ him sit on cold unpainted metal, probably not a \& good idea. He should wear conducting rubber footwear, or if this is not available, he is safer with shoes soled with leather especially if damp, than $\overrightarrow{\vec{\omega}}$ with ordinary rubber-soled footwear. The footstool, similarly, should be equipped with con- 8 ducting rubber leg tips, and should be made of 3 metal and not wood.

The anaesthetic machine should run on four conducting rubber tyres; should have conducting ${ }^{-}$ rubber corrugated tubing and face masks of the $\omega$ same material. In this way, the patient, table, $\mathrm{G}$ anaesthetist and anaesthetic machine form one $\frac{}{2}$ continuous electrical circuit, earthed to the floor.

All side equipment in the theatre should be, $\subseteq$ when possible, made of metal, and should run on metal castors, conducting rubber tyres or $\overrightarrow{0}$ should be provided with a drag chain of unpainte metal links. Special attention should be paid to the trolley on which the patient enters and leaves the theatre. It is very liable to become charged when a dry blanket is swept off the patient before he is put on to the operating table.

Everyone entering the theatre suite should wear overshoes of either conducting rubber or leather which can be damped.

If an explosion occurs in an operating theatre, the anaesthetist and the hospital management committee may find themselves involved in medi- $\frac{0}{3}$ colegal proceedings, and it is important that the accusing finger of the plaintiff's counsel should not be able to locate technical faults or lapses of judgment on the part of the theatre team.

Fire-fighting equipment must be always avail-o able and in good working order.

\section{BIBLIOGRAPHY} BULGIN, D., LLEWELLYN, F. J., THOMAS, GARFIELD
(I949), The Lan'et, May 7.
HOSPITALS, Fournal of the American Hospitals Association,
December, I949.
WOODBRIDGE, P. D., HORTON, J. W., CONNELL,
(1939), Fournal of the American Medical Association, II3,
740-744, August 26. 